\title{
Comparative semen cryopreservation in ferrets (Mustela putorius furo) and pregnancies after laparoscopic intrauterine insemination with frozen-thawed spermatozoa
}

\author{
J. G. Howard ${ }^{1 *}$, M. Bush ${ }^{1}$, C. Morton ${ }^{2}$, F. Morton ${ }^{2}$, K. Wentzel ${ }^{2}$ and \\ D. E. Wildt ${ }^{1}$ \\ ${ }^{i}$ National Zoological Park, Smithsonian Institution, Washington, DC 20008, USA; and \\ ${ }^{2}$ Path Valley Farm, Willow Hill, PA 17271, USA
}

\begin{abstract}
Summary. A study was conducted to determine an optimum technique for semen cryopreservation and the biological competence of frozen-thawed ferret spermatozoa. Fifty-two fresh electroejaculates from 4 males were evaluated for sperm percentage motility, forward progressive motility, motility index (SMI) and acrosomal integrity. To determine the optimum temperature for maintaining sperm motility in vitro and the influence of glycerol on sperm motility, seminal aliquants were diluted in TEST diluent (containing either 0 or $4 \%$ glycerol) and maintained at $25^{\circ}$ or $37^{\circ} \mathrm{C}$. For cryopreservation, semen was diluted in each of 3 cryodiluents (TEST, PDV, BF5F), cooled for $30 \mathrm{~min}$ at $5^{\circ} \mathrm{C}$ and pelleted on solid $\mathrm{CO}_{2}$ or frozen in $0.25 \mathrm{ml}$ straws $\left(20^{\circ} \mathrm{C} / \mathrm{min}\right.$ to $-100^{\circ} \mathrm{C}$ ). Following thawing, SMI and acrosomal integrity were determined. Ten females with maximum vulval swelling were given $90 \mathrm{i} . \mathrm{u}$. human chorionic gonadotrophin and laparoscopically inseminated in utero with spermatozoa previously frozen using the optimum diluent and freeze-thaw method. The maintenance temperature of $25^{\circ} \mathrm{C}$ was superior $(P<0.05)$ to $37^{\circ} \mathrm{C}$ for sustaining sperm motility, and glycerol did not influence $(P>0.05)$ motility for up to $11 \mathrm{~h}$ of culture. After thawing, motile spermatozoa were recovered in all treatment groups, but sperm motility and normal acrosomal ratings were highest using the PDV diluent, the pelleting method and thawing at $37^{\circ} \mathrm{C}(P<0.05)$. Seven of the 10 ferrets $(70 \%)$ inseminated with spermatozoa frozen by this approach became pregnant and produced 31 kits (mean litter size 4.4 ; range 1-9 kits). These results illustrate the sensitivity of ferret sperm motility and acrosomal integrity to different cryopreservation conditions; and demonstrate the biological competence of frozen-thawed ferret spermatozoa.
\end{abstract}

Keywords: ferret; sperm; semen cryopreservation; artificial insemination

\section{Introduction}

The reproductive cycle and the physiological mechanisms controlling seasonal variation in spermatogenesis and circulating testosterone profiles have been characterized in male ferrets (Mustela putorius furo) (Allanson, 1932; Baum \& Goldfoot, 1974; Walton, 1976; Erskine \& Baum, 1982; Sisk \& Desjardins, 1986; Kastner \& Apfelbach, 1987). Reproductive activity in this species is stimulated by a long-day photoperiod, most breeding occurring from March until August in the northern hemisphere (Neal et al., 1977). In our laboratory, the domestic ferret is being studied as a model for the endangered black-footed ferret (Mustela nigripes), a species considered extinct until a small

*Address for correspondence: Department of Animal Health, National Zoological Park, Smithsonian Institution, Washington, DC 20008 USA. 
population was rediscovered in Wyoming in 1981 (Clark, 1987). Artificial breeding strategies for this species and other rare mustelids would be valuable for: (i) propagating individuals which fail to mate because of a sexual incompatability or physical handicap; (ii) safely distributing gametes between different captive breeding sites without risking the transport of live animals; and (iii) storing germ plasm for use in subsequent animal generations, thereby offering a method of sustaining genetic diversity. The domestic ferret may serve as a model for developing artificial breeding techniques, because the species is genetically related to the black-footed ferret (O'Brien et al., 1989) and is readily available.

Recently, we reported that ferrets chronically maintained under a $16 \mathrm{~h}$ light: $8 \mathrm{~h}$ dark cycle were able to sustain spermatogenesis for as long as 65 weeks (Wildt et al., 1989). We determined that vaginal deposition of ferret spermatozoa was ineffective ( 0 pregnancies in 10 attempts) in females induced to ovulate with human chorionic gonadotrophin (hCG). However, 17 of 24 ferrets inseminated laparoscopically with fresh semen into the uterine horns became pregnant and delivered live young.

The objectives of the present study were to: (i) examine methods for sustaining motility of ferret spermatozoa in vitro; (ii) study the sensitivity of these spermatozoa to freeze-thawing by comparing various cryodiluents, freezing techniques and thawing temperatures; and (iii) assess the ability of thawed spermatozoa to fertilize ova in vivo and result in live offspring.

\section{Materials and Methods}

Semen collection and analysis. Four adult, proven breeder males (24-36 months old; $1 \cdot 2-1 \cdot 5 \mathrm{~kg}$ body wt) were maintained at the National Institutes of Health (NIH) Animal Center in Poolesville, MD, USA. Males were housed in individual cages $(91 \mathrm{~cm}$ deep $\times 87 \mathrm{~cm}$ wide $\times 79 \mathrm{~cm}$ high) containing a nest box and a $60-\mathrm{W}$ light bulb. Each male was exposed to an artificial photoperiod of $16 \mathrm{~h}$ light: $8 \mathrm{~h}$ dark. All animals had ad libitum access to water and a commercial dry mink chow (Milk Specialities Co. Dundee, IL, USA).

For electroejaculation, males were anaesthetized at intervals of 1-2 weeks with an intramuscular injection of tiletamine-zolazepam (Telazol ${ }^{\circledR}$ : A. H. Robbins, Richmond, VA, USA; $13 \mathrm{mg} / \mathrm{kg}$ ). Semen was collected by rectalprobe electroejaculation using techniques described previously (Wildt et al., 1989). Overall, 52 ejaculates were collected from 4 males (13 ejaculates/male). Seminal drops from each series were collected from the tip of the glans penis by capillary action into a warmed $\left(37^{\circ} \mathrm{C}\right)$ glass pipette. Each ejaculate was transferred into a $1.5 \mathrm{ml} \mathrm{microcentri-}$ fuge tube (Fisher Scientific, Pittsburg, PA, USA) containing either $120 \mu \mathrm{l}$ TEST (Graham et al., 1972), PDV (Nagase \& Niwa, 1963; Platz \& Seager, 1977) or BF5F (Howard et al., 1981) diluent at $37^{\circ} \mathrm{C}$.

The constituents of the diluents were as follows. TEST consisted of $20 \%$ egg yolk, $4 \cdot 83 \%$ tes-n-tris, $1 \cdot 15 \%$ tris, $0.4 \%$ glucose and $4 \%$ glycerol. PDV consisted of $20 \%$ egg yolk, $11 \%$ lactose and $4 \%$ glycerol. BF $5 \mathrm{~F}$, a modified BF5 diluent (Pursel \& Johnson, 1972), consisted of $20 \%$ egg yolk, $1.6 \%$ glucose, $1.6 \%$ fructose, $1.2 \%$ tes-n-tris, $0.2 \%$ tris, $4 \%$ glycerol and $0.5 \%$ surfactant mixture of sodium and triethanolamine lauryl sulphate, commonly referred to as Orvus ES Paste (Equex ${ }^{(\oplus)}$ : Nova Chemical Sales, Inc., Scitaute, MA, USA). Each millilitre of diluent contained 1000 i.u. penicillin G and $1000 \mu$ g streptomycin sulphate (Sigma Chemical Co., St. Louis, MO, USA). The justification for examining the diluent TEST was based on its previous use in domestic ferrets and its ability to sustain sperm motility of fresh semen for artificial insemination (Wildt et al., 1989). PDV was assessed because this diluent has been used for freezing carnivore semen, including dog and cat spermatozoa (Platz \& Seager, 1977; Platz et al., 1978). Diluent BF5F was tested because of its ability to provide maximum sperm motility after thawing and acrosomal protection in several nondomestic species (Howard et al., 1981, 1986b).

Immediately after collection, ejaculate volume and sperm concentration $/ \mathrm{ml}$ of ejaculate were determined using procedures described previously (Wildt et al., 1989). Diluted semen was assessed for percentage sperm motility and progressive motility $(0-5$ scale; $0=$ no forward motility, $5=$ rapid forward progressive motility). To determine an overall sperm assessment rating with equal emphasis on both sperm percentage motility and progressive motility, a sperm motility index $(\mathrm{SMI})$ was calculated: SMI $=[(\%$ sperm motility $)+($ progressive motility $\times 20) / 2]($ Howard et al., 1990). Sperm morphology and acrosomal integrity were assessed by fixing an aliquant $(2 \mu \mathrm{l})$ of each sample in $0.3 \%$ glutaraldehyde followed by phase-contrast microscopic examination of 200 spermatozoa/aliquant at $\times 1575$ (Howard et al., 1990). Cells were classified as normal or having a tightly coiled flagellum, bent midpiece with cytoplasmic droplet, bent midpiece without droplet, bent flagellum, residual proximal or distal droplet or an abnormal acrosome. The acrosomal ultrastructure of each spermatozoon was categorized into I of 4 classes: normal apical ridge (NAR), damaged apical ridge (DAR), missing apical ridge (MAR) or loose acrosomal cap (LAC) (Howard et al., 1981).

Semen processing. Diluted semen was assigned to 1 of 3 studies to determine the influence of maintenance temperature and addition of glycerol on longevity of sperm motility in vitro (Study 1); the impact of cryodiluent, freezing 
method and thawing temperature on post-thaw sperm motility and acrosomal integrity (Study 2); and the biological competence of frozen-thawed ferret sperm (Study 3 ).

Because each cryodiluent to be examined in Study 2 contained glycerol, it was important to determine in Study 1 whether this cryoprotectant had a detrimental effect on sperm motility. Additionally, maintenance at $37^{\circ} \mathrm{C}$ vs $25^{\circ} \mathrm{C}$ was compared to determine the appropriate condition for sustaining maximum sperm activity. To accomplish the objectives of Study 1, a total of 8 ejaculates from 4 males ( 2 ejaculates/male) was collected. Each ejaculate was split into 2 aliquants and each aliquant was diluted in $120 \mu \mathrm{l}$ TEST diluent containing either 0 or $4 \%$ glycerol. Each sample was split again into 2 aliquants and maintained at 37 or $25^{\circ} \mathrm{C}$. Sperm motility, progressive motility and SMI were determined hourly for $11 \mathrm{~h}$.

In Study 2, 36 ejaculates from 4 males ( 9 samples/male) were collected for comparison of cryopreservation techniques. Seminal samples were diluted in either $120 \mu \mathrm{l}$ TEST, PDV or BF5F containing $4 \%$ glycerol. Therefore, the assessment of each cryodiluent was based on the total of 12 ejaculates from 4 males ( 3 replicates/male/cryodiluent). All aliquants were cooled for $30 \mathrm{~min}$ at $5^{\circ} \mathrm{C}$ and either pelleted on solid $\mathrm{CO}_{2}$ or frozen in plastic straws. The pellet method (Nagase \& Niwa, 1963; Howard et al., 1986a, b) involved pipetting single drops $(\sim 30 \mu 1)$ of cooled, diluted semen into $3 \times 4 \mathrm{~mm}$ indentations in a block of solid $\mathrm{CO}_{2}$. After a 3 min freezing interval, the solid $\mathrm{CO}_{2}$ block was inverted, depositing the frozen pellets in a liquid nitrogen bath. The pellets were spoon-transferred into sterile, labelled vials (Nalgene ${ }^{\circledR}$ : Sybron Corp., Rochester, NY, USA) and stored in a container of liquid nitrogen. The straw freezing method involved manually filling diluted seminal samples into $0.25 \mathrm{ml}$ French straws (I.M.V. International Corp., Minneapolis, MN, USA). Each straw initially was filled with $100 \mu$ cryodiluent containing no semen, followed by an air space and then the diluted semen $(100 \mu \mathrm{l} / \mathrm{straw})$. Straws were heat-sealed, cooled for $30 \mathrm{~min}$ at $5^{\circ} \mathrm{C}$ and transferred to a programmable, controlled-rate freezing unit (Planer Products Kryo-10, TS Scientific, Perkasie, PA, USA) preset in a holding phase at $5^{\circ} \mathrm{C}$. Straws were frozen to $-100^{\circ} \mathrm{C}$ at $20^{\circ} \mathrm{C} / \mathrm{min}$, plunged into liquid nitrogen and stored.

Assessment of thawed spermatozoa. To compare 2 thawing methods, semen frozen in pellets and straws was thawed at either $37^{\circ} \mathrm{C}$ for $30 \mathrm{sec}$ or $60^{\circ} \mathrm{C}$ for $3 \mathrm{sec}$. Three pellets from each aliquant were thawed rapidly in a warmed, sterile $12 \times 75 \mathrm{~mm}$ glass culture tube containing $220 \mu \mathrm{l}$ phosphate-buffered saline. Aliquants in straws were thawed by placing in a waterbath before transferring semen to a glass culture tube. Within each cryodiluent-freezing method treatment group, assessment of thawing method was based on split samples from the same ejaculate thawed at 37 and $60^{\circ} \mathrm{C}$. Immediately after thawing, an aliquant from each sample was fixed in $0.3 \%$ glutaraldehyde for later assessment of sperm acrosomal integrity. All aliquants were maintained at $25^{\circ} \mathrm{C}$ and examined for sperm percentage motility, progressive motility and SMI at 0,30 and $60 \mathrm{~min}$ after thawing to determine the longevity of sperm motility in vitro.

Artificial insemination. Using the optimum freeze-thawing technique detected in Study 2, 8 additional ejaculates from 4 males were collected for cryopreservation and laparoscopic intrauterine insemination of 10 females (Study 3 ). Two of these 8 ejaculates were of sufficient volume for inseminating 4 females ( 2 inseminations/ejaculate). After thawing, seminal samples were removed from the waterbath, evaluated for percentage sperm motility, progressive motility and SMI, and then maintained at $25^{\circ} \mathrm{C}$ for $20 \mathrm{~min}$ before artificial insemination (AI). The total number of motile sperm inseminated in each female was determined.

Female ferrets (24-36 months old; 0.9-1.3 kg body wt) were maintained at Path Valley Farm (Willow Hill, PA,

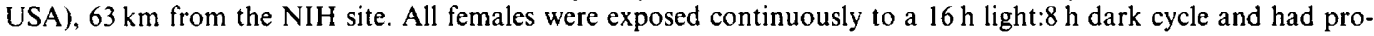
duced at least one litter within 6 months of AI. Ferrets were monitored daily for vulval tumescence, and those with maximum vulval swelling were considered in oestrus. On the day of AI, ferrets were transported to the NIH Animal Center. Each female was anaesthetized with Telazol $(10 \mathrm{mg} / \mathrm{kg})$, surgically prepared and then subjected to laparoscopic AI using techniques described earlier (Wildt et al., 1989). In brief, each uterine horn was identified and cannulated for intrauterine deposition of semen using a sterile, feline indwelling catheter (Sovereign ${ }^{\circledR}$, Sherwood Medical, St. Louis, MO, USA; 20 gauge, $5 \mathrm{~cm}$ long). Each catheter was inserted percutaneously into the uterine lumen proximal to the uterine bifurcation under laparascopic observation. Sterile, polyethylene tubing (PE-10, Intramedic ${ }^{\circledR}$, Clay Adams, Parasippany, NJ, USA) containing $100 \mu \mathrm{l}$ frozen-thawed semen was passed through the catheter into the lumen of each uterine horn for insemination. An intramuscular injection of 90 i.u. hCG (Sigma Chemical Co., St. Louis, MO, USA) was given at the time of AI to induce ovulation.

Statistical analysis. Values are reported as means \pm standard error of the means (s.e.m.). The influence of temperature and glycerol on sperm motility and the effect of cryopreservation treatment on sperm survival after thawing were assessed statistically by the analysis of variance (ANOVA) in a randomized complete block design using a computerized statistical program (Statistical Analysis System; SAS, 1986). Because of variation in ejaculate characteristics among individuals, each animal was considered as one complete replicate (block). When a significant $\mathbf{F}$ value was calculated $(P<0.05)$, differences among means for selected pairwise comparisons were determined by a Duncan's multiple range test (SAS, 1986). Differences in sperm traits and number of motile spermatozoa inseminated between pregnant and nonpregnant females were analysed using Student's $t$ test.

\section{Results}

Semen containing motile spermatozoa was obtained from each ferret at each electroejaculation. Based on a total of 52 electroejaculates, mean ejaculate characteristics are provided in Table 1. 
Seminal traits including sperm motility, progressive motility, motility index and morphology were not influenced $(P>0.05)$ by dilution in TEST, PDV or BF5F diluent. Fewer than $33 \%$ of all spermatozoa were pleiomorphic, and the most prevalent abnormality included cells with a residual cytoplasmic droplet (Table 1). Microscopic assessment of the ultrastructure of spermatozoa revealed a prominent acrosome, which could be identified readily and classified by phase-contrast microscopy (Fig. 1). A high proportion of spermatozoa had a normal apical ridge (Table 1).

Table 1. Ejaculate traits, sperm morphology and acrosomal integrity in the ferret $(n=52$ ejaculates)

\begin{tabular}{lr}
\hline Ejaculate volume $(\mu \mathrm{l})$ & $50 \cdot 1 \pm 3 \cdot 7$ \\
Sperm concentration $\left(\times 10^{-6} / \mathrm{ml}\right)$ & $706 \cdot 1 \pm 50 \cdot 5$ \\
$\quad$ motility $(\%)$ & $80 \cdot 7 \pm 1 \cdot 0$ \\
$\quad$ progressive motility & $3 \cdot 3 \pm 0 \cdot 1$ \\
$\quad$ motility index & $73 \cdot 6 \pm 1 \cdot 0$ \\
Motile spermatozoa/ejaculate $\left(\times 10^{-6}\right)$ & $27 \cdot 7 \pm 2 \cdot 8$ \\
Structurally normal spermatozoa $(\%)$ & $67 \cdot 3 \pm 1 \cdot 3$ \\
Abnormal spermatozoa $(\%)$ & \\
Abnormal acrosome & $7 \cdot 6 \pm 0 \cdot 3$ \\
Tightly coiled flagellum & $0 \cdot 7 \pm 0 \cdot 1$ \\
Bent midpiece with droplet & $2 \cdot 7 \pm 0 \cdot 2$ \\
Bent midpiece without droplet & $0 \cdot 8 \pm 0 \cdot 2$ \\
Bent flagellum & $1 \cdot 8 \pm 0 \cdot 2$ \\
Proximal cytoplasmic droplet & $8 \cdot 7 \pm 0 \cdot 5$ \\
Distal cytoplasmic droplet & $10.4 \pm 0 \cdot 8$ \\
Acrosomal integrity $(\%)$ & \\
Normal apical ridge & \\
Damaged apical ridge & $92 \cdot 4 \pm 0 \cdot 5$ \\
Missing apical ridge & $4 \cdot 7 \pm 0 \cdot 4$ \\
Loose acrosomal cap & $0 \cdot 8 \pm 0 \cdot 1$ \\
\hline
\end{tabular}

Values are means \pm s.e.m.

In Study 1, regardless of glycerol treatment, maintenance at $25^{\circ} \mathrm{C}$ was better $(P<0.05)$ than at $37^{\circ} \mathrm{C}$ for sustaining sperm motility in vitro (Fig. 2). Following dilution in TEST egg-yolk diluent, motility of spermatozoa was maintained for more than $11 \mathrm{~h}$ using the $25^{\circ} \mathrm{C}$ holding temperature. Within temperature treatments, the presence of glycerol had no effect $(P>0.05)$ on in vitro sperm motility.

In Study 2, there was no difference $(P>0.05)$ in prefreeze $\%$ sperm motility, progressive motility and SMI after dilution among the TEST (83.6 $\pm 1 \cdot 3,3 \cdot 4 \pm 0 \cdot 1,76 \cdot 0 \pm 0 \cdot 9$, respectively), $\operatorname{PDV}(79 \cdot 0 \pm 1 \cdot 0,3 \cdot 1 \pm 0 \cdot 1,70 \cdot 5 \pm 1 \cdot 0$, respectively) and BF5F $(76 \cdot 7 \pm 1 \cdot 6,3 \cdot 6 \pm 0 \cdot 1,74 \cdot 0 \pm 1 \cdot 3$ respectively) diluents. Motile spermatozoa were recovered after cryopreservation in all treatment groups, but post-thaw sperm viability was influenced $(P<0.01)$ by cryodiluent, freezing method and thawing temperature. Maximum post-thaw survival, based on the maximum motility index, was achieved with PDV, pelleting and thawing at $37^{\circ} \mathrm{C}$ (Fig. 3).

Cryopreservation technique also influenced $(P<0.01)$ acrosomal integrity after thawing (Fig. 4). The mean, \pm s.e.m., proportion of spermatozoa with normal apical ridges (NAR) after thawing ranged from $10 \cdot 5 \pm 1.9 \%$ to $41 \cdot 0 \pm 5 \cdot 3 \%$ (Fig. 4). Freeze-thawing technique also affected $(P<0 \cdot 01)$ the DAR, MAR and LAC values (Fig. 4). Overall, PDV-pellets thawed at $37^{\circ} \mathrm{C}$ provided maximum acrosomal protection as demonstrated by the highest incidence of NAR (Fig. 4).

The longevity of post-thaw sperm motility in vitro also was highly dependent $(P<0.01)$ on cryotechnique at 30 and $60 \mathrm{~min}$ after warming. Compared with the other treatments at the same interval, pelleted semen diluted in PDV and thawed at $37^{\circ} \mathrm{C}$ demonstrated the greatest SMI ratings at 60 min after thawing (Fig. 5). 


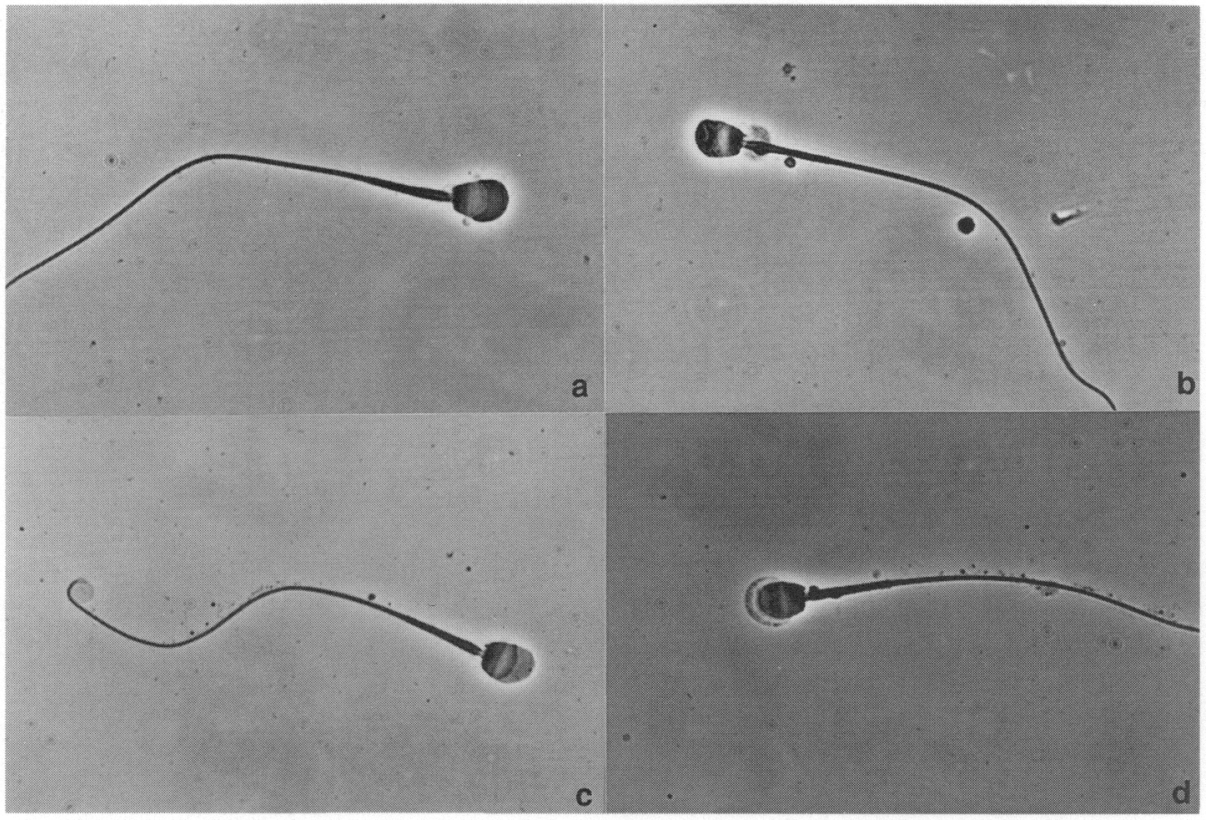

Fig. 1. Acrosomal morphology of ferret spermatozoa exhibiting a normal (a), damaged (b), or missing apical ridge $(c)$ or loose acrosomal cap $(d) ;(\times 1575)$.
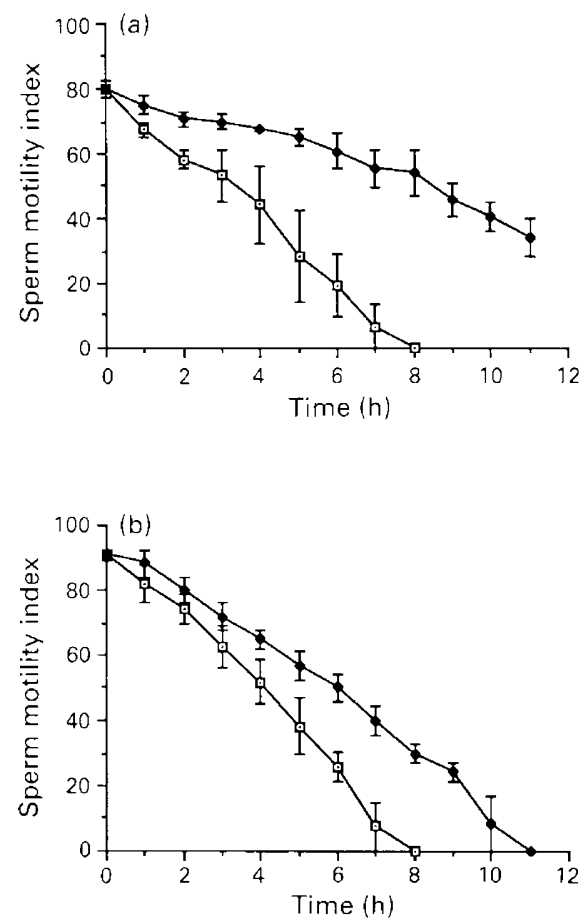

Fig. 2. Influence of maintenance temperature $\left(25^{\circ} \mathrm{C}(\bullet)\right.$ vs $\left.37^{\circ} \mathrm{C}(\square)\right)$ without (a) or (b) with $4 \%$ glycerol on longevity of ferret sperm motility in vitro. Sperm motility index is a mean of percentage sperm motility and sperm progressive motility $\times 20 ; n=8$ total ejaculates. 


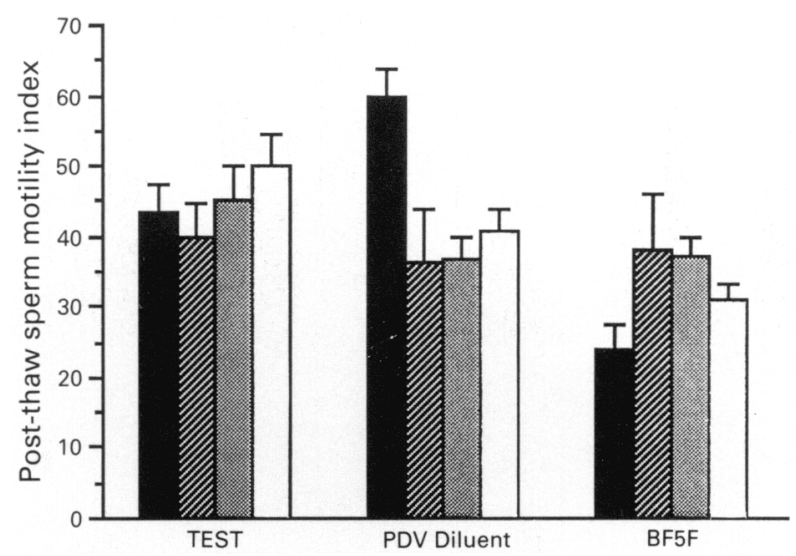

Fig. 3. Influence of cryodiluent, freezing in pellet or straw container and thawing temperature

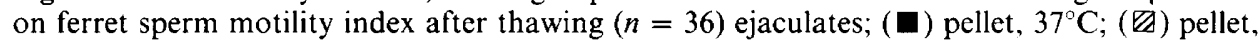
$60^{\circ} \mathrm{C}$; (回) straw, $37^{\circ} \mathrm{C} ;(\square)$ straw, $60^{\circ} \mathrm{C}$.

Table 2. Results of laparoscopic artificial insemination ( $n=10$ females) with frozen-thawed ferret sperm

\begin{tabular}{|c|c|}
\hline $\begin{array}{l}\text { Mean sperm motility index* after } \\
\text { thawing }\end{array}$ & $\begin{array}{l}58 \cdot 8 \pm 2 \cdot 2 \\
(50 \cdot 0-72 \cdot 5)\end{array}$ \\
\hline $\begin{array}{l}\text { Mean number of motile sperm } \\
\text { inseminated }\left(\times 10^{-6}\right)\end{array}$ & $\begin{array}{l}3.5 \pm 0.6 \\
(1.4 .6 .0)\end{array}$ \\
\hline $\begin{array}{l}\text { Mean percentage morphologically } \\
\text { normal sperm inseminated }\end{array}$ & $\begin{array}{l}68 \cdot 3 \pm 2 \cdot 1 \\
(52 \cdot 5-75 \cdot 5)\end{array}$ \\
\hline $\begin{array}{l}\text { Mean number of inseminated motile } \\
\text { sperm with normal apical ridge } \\
\left(\times 10^{-6}\right)\end{array}$ & $\begin{array}{l}1 \cdot 5 \pm 0 \cdot 5 \\
(0 \cdot 5-3 \cdot 1)\end{array}$ \\
\hline $\begin{array}{l}\text { Proportion of anovulatory females } \\
\text { after treatment with human } \\
\text { chorionic gonadotrophin }\end{array}$ & $1 / 10$ \\
\hline $\begin{array}{l}\text { Total number of pregnant females (\% } \\
\text { pregnant) }\end{array}$ & $7(70 \cdot 0 \%)$ \\
\hline Mean gestation (days) & $\begin{array}{c}42.9 \pm 0.59 \\
(4 !-45)\end{array}$ \\
\hline Mean number of kits/litter & $\begin{array}{c}4 \cdot 4 \pm 1 \cdot 0 \\
(I-9)\end{array}$ \\
\hline
\end{tabular}

Because PDV-pellets thawed at $37^{\circ} \mathrm{C}$ provided the greatest cryoprotection in all categories, this method was used for the fertility study (Study 3 ). Table 2 provides relevant information on the number and quality of thawed sperm inseminated and the pregnancy results. Seven of 10 females conceived after laparoscopic AI and produced live young ( $70 \%$ pregnancy/offspring). There was no difference $(P>0.05)$ in motility traits or number of spermatozoa inseminated between pregnant and nonpregnant females (data not shown). Of the 3 ferrets which failed to become pregnant, 1 female did not ovulate after hCG administration and remained in oestrus following AI. The remaining 2 females ovulated, as evidenced by vulval detumescence, but neither became pregnant. In the 2 cases in which the ejaculate from 2 males was frozen-thawed and split for AI of 2 females, all 4 females became pregnant. The maximum length of time semen was maintained frozen before thawing and successful AI was 10 months. 

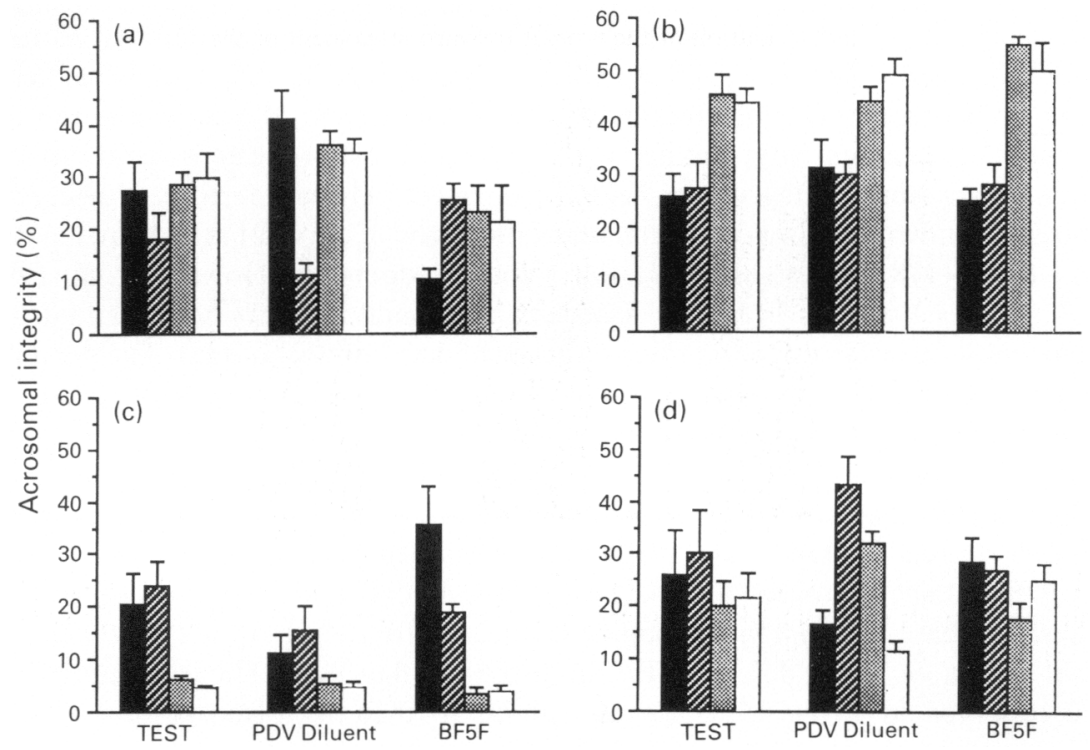

Fig. 4. Influence of cryodiluent, freezing in pellet or straw container and thawing temperature on ferret acrosomal integrity after thawing ( $n=36$ ejaculates); (a) normal, (b) damaged and (c) missing apical ridge and (d) loose acrosomal cap. See Fig. 3 for key.

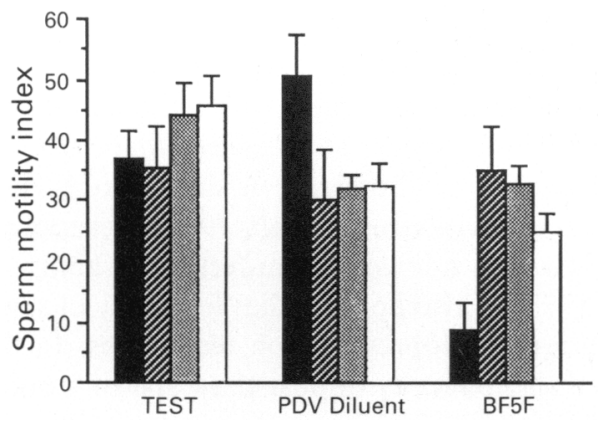

Fig. 5. Ferret sperm motility index in vitro at $60 \mathrm{~min}$ after thawing; symbols as in Fig. 3.

\section{Discussion}

The successful freezing of carnivore semen and its use for producing offspring have been limited to the dog (Platz \& Seager, 1977), cat (Platz et al., 1978), fox (Aamdal et al., 1972) and wolf (Seager et al., 1975). To our knowledge, this is the first attempt to determine an optimum method for cryopreserving ferret spermatozoa and assessing its biological competence. The use of a multitrait analysis system allowed the assessment of sperm motility immediately after thawing and the longevity of sperm motility in addition to categorizing the acrosomal damage induced by cryopreservation. Studying the viability of spermatozoa in vitro in a comparative fashion before attempting artificial insemination probably accelerated our ability to produce ferret offspring efficiently. A particularly important observation was the close relationship between post-thaw motility ratings and acrosomal integrity. Identifying PDV as the superior diluent was facilitated by in-vitro studies demonstrating that both sperm motility ratings and number of normal acrosomes 
were highest using this diluent. Pursel et al. (1972) demonstrated that motility alone is an inadequate index of sperm survival after thawing, as highly motile cells can be afflicted with a severely damaged acrosome. During freezing of the spermatozoon, the acrosome can deteriorate progressively so that the apical ridge can become damaged or lost or the acrosomal cap can become loosened. Because acrosomal integrity has been correlated closely with fertility (Pursel et al., 1972), this characteristic is now used as a complementary indicator of survival after thawing in domestic (Pursel et al., 1972, 1978; Berndtson et al., 1981) and nondomestic (Howard et al., 1981, 1986b; Schiewe et al., in press) species. In ferrets, assessing acrosomal integrity before and after freezing was an extremely useful criterion for comparing cryopreservation techniques. The prominent acrosome of the ferret spermatozoon appeared more similar to cattle (Saacke \& Marshall, 1968) and pigs (Pursel et al., 1972) than to domestic and nondomestic felids (Wildt et al., 1983, 1986, 1988; Howard et al., 1990), equids (Howard et al., 1981) or non-human primates (Leverage et al., 1972). Although Giemsa stain has been used to evaluate the integrity of acrosomes in domestic ferrets and black-footed ferrets (Curry et al., 1989), we determined that phase-contrast microscopy of glutaraldehyde-fixed spermatozoa allowed easy assessment and classification of acrosomal damage. Likewise, phase-contrast microscopy was effective for determining structural morphology of ferret spermatozoa including defects in the midpiece and flagellum. The total number of normal spermatozoa observed in ferrets $(67 \cdot 3 \%)$ was similar to that in normospermic domestic felids $(71.6 \%)$, but the proportion of proximal and distal cytoplasmic droplets was greater in the ferrets than in domestic cats (Howard et al., 1990). Although the aetiology of specific spermatozoal defects is unknown, the electroejaculation technique does not appear to influence the incidence of abnormal spermatozoa, since certain carnivores trained to ejaculate into an artificial vagina produce numbers of defective spermatozoa similar to those in electroejaculates (Wildt et al., 1983; Durrant et al., 1985; Howard et al., 1990).

The time that spermatozoa remain viable in vitro is a critical factor for in-vitro gamete interaction studies or artificial breeding. The present study demonstrated that sperm viability during incubation is influenced by maintenance temperature, the duration of sperm motility being extended significantly by maintaining sperm at 25 rather than $37^{\circ} \mathrm{C}$. This observation, which is probably mediated by a reduction in metabolic rate, is similar to recent findings in other carnivore species, including the domestic cat (Goodrowe et al., 1989). Because poor sperm survival during incubation in vitro is associated with a lower sperm-fertilizing ability in certain domestic species (Larsson, 1976; Pursel et al., 1978), it also appears that longevity of sperm survival is an important criterion for determining optimum cryopreservation techniques. In this study, there also was a significant interaction between the longevity of post-thaw sperm motility in vitro and cryodiluent/ freeze-thaw method. The $\mathrm{PDV} /$ pellet $/ 37^{\circ} \mathrm{C}$ method, which resulted in the highest SMI ratings immediately after thawing, also sustained maximum sperm viability after thawing, including for at least $60 \mathrm{~min}$ in vitro and apparently even longer in vivo. Because ovulation in ferrets occurs $24-36 \mathrm{~h}$ after an hCG injection (Chang \& Yanagimachi, 1963; Chang, 1965) and because these females were administered hCG at the time of AI, it is reasonable that the fertilizable life-span of the thawed spermatozoa was maintained for at least $24 \mathrm{~h}$ in the female reproductive tract. This interval was similar to the in-vivo longevity exhibited by fresh ferret spermatozoa used in an earlier laparoscopic insemination study (Wildt et al., 1989).

The utility of the PDV-pelleting technique for cryopreserving ferret spermatozoa was similar to earlier reports involving domestic dogs and cats (Platz \& Seager, 1977; Platz et al., 1978). Interestingly, the straw container technique provided results inferior to those obtained after pelleting. Comparative cryopreservation studies in other species, including the African elephant (Loxodonta africana), have demonstrated that pelleting is superior to the straw method for sperm freezing (Howard et al., 1986b). The cooling rate during freezing is one of the most important factors controlling the life or death of cells (Mazur, 1985). Most sperm damage during freezing occurs from -3 to $-20^{\circ} \mathrm{C}$ for boar sperm (Pursel \& Park, 1985) and from -10 to $-35^{\circ} \mathrm{C}$ for bull sperm (O'Dell et al., 1958; Parkinson \& Whitfield, 198\%). The marked loss of motility and increased 
acrosomal derangement during this time appears to be related to the onset of ice crystal formation in the cryodiluent (Niwa \& Taguchi, 1981). Compared with the straw freezing rate used in this study, the pellet method may have provided faster freezing (Nagase \& Niwa, 1963), resulting in a shorter duration of the freezing point plateau and reduced sperm damage.

This study proved that thawed ferret spermatozoa were biologically competent, as demonstrated by a $70 \%$ pregnancy rate after $\mathrm{AI}$. The incidence of pregnancy in this study was similar to that in an earlier study $(70.8 \%)$ in which ferrets were inseminated by the same approach but using freshly ejaculated spermatozoa (Wildt et al., 1989). Our study was not designed to determine the minimum number of thawed, motile sperm necessary to achieve pregnancy. Nevertheless, conceptions occurred using as few as $1.4 \times 10^{6}$ motile sperm. Although ferrets produce a low-volume ejaculate, we have demonstrated in an earlier study (Wildt et al., 1989) that the ejaculate of a single male can be divided and used to produce dual pregnancies using as few as $1.6 \times 10^{6} \mathrm{sperm} / \mathrm{female}$. The pelleting method of sperm freezing proved to be equally effective in maximizing the usefulness of the small-volume ejaculate. On both occasions when thawed ejaculates were split and used to inseminate 2 ferrets, all females became pregnant.

In summary, these results demonstrated that domestic ferret sperm responded differently to variations in cryodiluent, freezing technique and warming procedure. The PDV diluent and pelleting technique provided the overall highest post-thaw survival characteristics for ferret spermatozoa. Most importantly, this study demonstrated the potential of using a multitrait assessment strategy combined with comparative freezing and in-vitro testing trials for formulating effective sperm-freezing protocols. Such a pre-emptive approach appears particularly appropriate if largescale, germ plasm banking and AI are planned for a related wild and/or rare species. In this case, we speculate that the described techniques can be applied to improving the captive management of the endangered black-footed ferret. The PDV-pellet method is currently being used to cryopreserve black-footed ferret semen.

We thank S. Hurlbut for valuable expertise and assistance with the laparoscopic inseminations and the staff of the National Institutes of Health Animal Center and Path Valley Farm and Dr E. T. Thorne (Wyoming Department of Fish and Game) for assisting with various aspects of this study. This research was funded by grants from the US Fish \& Wildlife Service (National Ecology Center) and the Friends of the National Zoo.

\section{References}

Aamdal, J., Anderson, K. \& Fougner, J.A. (1972) Insemination with frozen semen in the blue fox. Proc. 7 th Int. Cong. Anim. Reprod. Artif. Insem., Munich, 2, 1713-1716.

Allanson, M. (1932) The reproductive processes of certain mammals. III. The reproductive cycle of the male ferret. Proc. R. Soc. Ser. B 110, 295-314.

Baum, M.J. \& Goldfoot, D.A. (1974) Effect of hypothalamic lesions on maturation and annual cyclicity of the ferret testis. J. Endocr. 62, 59-73.

Berndtson, W.E., Olar, T.T. \& Pickett, B.W. (1981) Correlation between post-thaw motility and acrosomal integrity of bovine sperm. J. Dairy Sci. 64, 346-349.

Chang, M.C. (1965) Fertilizing life of ferret sperm in the female tract. J. exp. Zool. 158, 87-100.

Chang, M.C. \& Yanagimachi, R. (1963) Fertilization of ferret ova by deposition of epididymal sperm into the ovarian capsule with special reference to the fertilizable life of ova and the capacitation of sperm. J. exp. Zool. 154, 175-188.
Clark, T.W. (1987) Black-footed ferret recovery: a progress report. Conserv. Biol. 1, 8-11.

Curry, P.T., Ziemer, T., Van der Horst, G., Burgess, W., Straley, M., Atherton, R.W. \& Kitchin, R.M. (1989) A comparison of sperm morphology and silver nitrate staining characteristics in the domestic ferret and the black-footed ferret. Gam. Res. 22, 27-36.

Durrant, B.S., Schuerman, T. \& Millard, D. (1985) Noninvasive semen collection in the cheetah. Proc. $A$. Mtg. Am. Assoc. Zoo Pks. Aquar., Columbus, pp. $654-657$.

Erskine, M.S. \& Baum, M.J. (1982) Plasma concentrations of testosterone and dihydrotestosterone during perinatal development in male and female ferrets. Endocrinology 111, 767-772.

Goodrowe, K.L., Howard, J.G., Schmidt, P.M. \& Wildt, D.E. (1989) The reproductive biology of the domestic cat with special reference to endocrinology, sperm function and in-vitro fertilization. $J$. Reprod. Fert., Suppl. 39, 73-90. 
Graham, E.F., Crabo, B.G. \& Brown, K.I. (1972) Effect of some zwitter-ion buffers on the freezing and storage of spermatozoa. J. Dairy Sci. 55, 372-378.

Howard, J.G., Pursel, V.G., Wildt, D.E. \& Bush, M. (1981) Comparison of various extenders for freeze preservation of semen from selected captive wild ungulates. J. Am. Vet. Med. Assoc. 179, 1157-1161.

Howard, J.G., Bush, M. \& Wildt, D.E. (1986a) Semen collection, analysis and cryopreservation in nondomestic mammals. In Current Therapy in Theriogenology, pp. 1047-1053. Ed. D. Morrow. W. B. Saunders Co., Philadelphia.

Howard, J.G., Bush, M., de Vos, V., Schiewe, M.C., Pursel, V.G. \& Wildt, D.E. (1986b) Influence of cryoprotective diluent on post-thaw viability and acrosomal integrity of spermatozoa from the African elephant (Loxodonta africana). J. Reprod. Fert. 78, 295-306.

Howard, J. G. Brown, J.L., Bush, M. \& Wildt, D.E. (1990) Teratospermic and normospermic domestic cats: ejaculate traits, pituitary-gonadal hormones and improvement of spermatozoal motility and morphology after swim-up processing. J. Androl. 11, 204-215.

Kastner, D. \& Apfelbach, R. (1987) Effects of cyproterone acetate on mating behavior, testicular morphology, testosterone level and body temperature in male ferrets in comparison with normal and castrated males. Horm. Res. 25, 178-184.

Larsson, K. (1976) Fertility of deep-frozen boar spermatozoa at various intervals between insemination and induced ovulation. Influence of boars and thawing diluents. Acta Vet. Scand. 17, 63-73.

Leverage, W.E., Valerio, D.A., Schultz, A.P., Kingsbury, E. \& Dorey, C. (1972) Comparative study on the freeze preservation of spermatozoa: primate, bovine and human. Lab. Anim. Sci. 22, 882-889.

Mazur, P. (1985) Basic concepts in freezing cells. Proc. 1st Int. Conf. Deep Freezing Boar Semen, Uppsala, pp. 91-111.

Nagase, H. \& Niwa, T. (1963) Studies on the deepfreezing technique for bull semen. III. Deep freezing of bull semen in pellet form. Jap. J. anim. Reprod. 9, 73-77.

Neal, J., Murphy, B.D., Moger, W.H. \& Oliphant, L.W. (1977) Reproduction in the male ferret: gonadal activity during the annual cycle: Recrudescence and maturation. Biol. Reprod. 17, 380-385.

Niwa, T. \& Taguchi, K. (1981) Cryomicroscopic observation on processes of freezing and thawing of boar semen. Bull. Artif. Insem. Lab. Iwate Univ. 1, 21-35.

O'Brien, S.J., Martenson, J. S., Eichelberger, M. A., Thorne, E. T. \& Wright, F. (1989) Biochemical genetic variation and molecular systematics of the black-footed ferret, Mustela nigripes. In Conservation Biology and the Black-Footed Ferret, pp. 21-33. Eds U. S. Seal, E. T. Thorne, M. A. Bogan \& S. H. Anderson. Yale University Press, New Haven.

O'Dell, W.T., Almquist, J.O. \& Marsh, L.A. (1958) Freezing bovine semen. III. Effect of freezing rate on bovine spermatozoa frozen and stored at $-79^{\circ} \mathrm{C} . J$. Dairy Sci. 41, 79-89.

Parkinson, T.J. \& Whitfield, C.H. (1987) Optimisation of freezing conditions for bovine spermatozoa. Theriogenology 27, 781-797.
Platz, C.C. \& Seager, S.W.J. (1977) Successful pregnancies with concentrated frozen canine semen. $L a b$. Anim. Sci. 27, 1013-1016.

Platz, C.C., Wildt, D.E. \& Seager, S.W.J. (1978) Pregnancy in the domestic cat after artificial insemination with previously frozen spermatozoa. J. Reprod. Fert. 52, 279-282.

Pursel, V.G. \& Johnson, L.A. (1972) Fertility comparison of boar semen frozen in two extenders. J. Anim. Sci. 35, 1123 (abstr.).

Pursel, V.G. \& Park, C.S. (1985) Freezing and thawing procedure for boar spermatozoa. Proc. Ist Int. Cong. Deep Freezing Boar Semen, Uppsala, pp. 147-166.

Pursel, V.G., Johnson, L.A. \& Schulman, L.L. (1972) Loss of boar sperm fertilizing capacity associated with altered acrosome morphology during in vitro storage. Proc. 7th Int. Cong. Anim. Reprod. Artif. Insem., Munich, 2, 1595-1600.

Pursel, V.G., Schulman, L.L. \& Johnson, L.A. (1978) Effect of Orvus ES Paste on acrosome morphology, motility and fertilizing capacity of frozen-thawed boar sperm. J. Anim. Sci. 47, 198-202.

Saacke, R.G. \& Marshall, C.E. (1968) Observations on the acrosomal cap of fixed and unfixed bovine spermatozoa. J. Reprod. Fert. 16, 511-514.

SAS. (1986) SAS User's Guide. Statistical Analysis System Institute, Inc., Cary, N.C.

Schiewe, M.C., Bush, M., de Vos, V., Brown, J.L. \& Wildt, D.E. (in press) Semen characteristics, sperm freezing and endocrine profiles in free-ranging wildebeest (Connechaetes taurinus) and greater kudu (Tragelaphus strepsiceros). J. Zoo Wildl. Med.

Seager, S.W.J., Platz, C.C. \& Hodge, W. (1975) Successful pregnancy using frozen semen in the wolf. Int. Zoo Yrbk. 15, 140-143.

Sisk, C.L. \& Desjardins, C. (1986) Pulsatile release of luteinizing hormone and testosterone in male ferrets. Endocrinology 119, 1195-1203.

Walton, K.C. (1976) The reproductive cycle in the male polecat Putorius putorius in Britain. J. Zool., Lond. 180, 498-503.

Wildt, D.E., Bush, M., Howard, J.G., O'Brien, S.J., Meltzer, D., van Dyk, A., Ebedes, H. \& Brand, D.J. (1983) Unique seminal quality in the South African cheetah and a comparative evaluation in the domestic cat. Biol. Reprod. 29, 1019-1025.

Wildt, D.E., Howard, J.G., Hall, L.L. \& Bush, M. (1986) The reproductive physiology of the clouded leopard. I. Electroejaculates contain high proportions of pleiomorphic spermatozoa throughout the year. Biol. Reprod. 34, 937-947.

Wildt, D.E., Phillips, L.G., Simmons, L.G., Chakraborty, P.K., Brown, J.L., Howard, J.G., Teare, A. \& Bush, M. (1988) A comparative analysis of ejaculate and hormonal characteristics of the captive male cheetah, tiger, leopard and puma. Biol. Reprod. 38, 245-255.

Wildt, D.E., Bush, M., Morton, C., Morton, F. \& Howard, J.G. (1989) Semen characteristics and testosterone profiles in ferrets kept in a long-day photoperiod, and the influence of hCG timing and sperm dilution medium on pregnancy rate after laparoscopic insemination. J. Reprod. Fert. 86, 349-358.

Received 23 July 1990 